\title{
CONTRIBUCIÓN AL ESTUDIO DE LA SALIDA DELICTIVA DE OBRAS DE ARTE AL EXTRANJERO DURANTE LA GUERRA CIVIL
}

\author{
Arturo Colorado Castellary ${ }^{1}$ \\ Universidad Complutense de Madrid
}

\begin{abstract}
El tráfico ilegal de obras de arte al extranjero durante la Guerra Civil española no ha sido todavía objeto de investigaciones sistemáticas, debido en gran parte a su evidente dificultad investigadora por la escasa, dispersa y en parte poco fiable documentación de archivo. El propósito de este artículo es aportar una nueva documentación en gran parte inédita que ayude al estudio de esta difícil cuestión, basándose principalmente en fuentes primarias. La primera tarea radica en diferenciar claramente entre la evacuación oficial para hacer escapar las obras del peligro de la guerra y la salida delictiva de obras de arte, a pesar de que para el franquismo todo era producto del "robo de los rojos"; la segunda, establecer cuáles fueron los principales actuantes en este tráfico ilegal y sus medios y procedimientos. Y, finalmente, analizar las actuaciones de ambos gobiernos para combatir la salida ilegal de obras de arte al extranjero.
\end{abstract}

Palabras clave: Patrimonio; Guerra Civil; Expolio artístico; Propaganda; Recuperación artística.

\section{CONTRIBUTION TO THE STUDY OF THE ILLEGAL EXPORT OF ARTWORKS DURING THE SPANISH CIVIL WAR}

The illegal trafficking of works of art abroad during the Spanish Civil War has not yet been studied systematically due in part to the evident difficulties for research given the scarce, dispersed and, in many cases, unreliable documentation in archives. The purpose of this article is to establish research parameters in order to confront these difficulties, based mainly on unpublished primary sources. The first task lies in clearly differentiating between official shipments of artworks to save them from the dangers of war, and other illegal shipments, taking into account that for the Franco regime everything was the product of the "theft of the reds". The second task is to establish who were those mainly responsible for this illegal trafficking, their means and procedures. The final purpose is to analyze the actions taken by both governments to fight the illegal export of artworks.

Key words: Cultural Heritage; Spanish Civil War; Art plundering; Propaganda, Recovering artworks.

Cómo citar este artículo / Citation: Colorado Castellary, Arturo (2017): "Contribución al estudio de la salida delictiva de obras de arte al extranjero durante la Guerra Civil”. En: Archivo Español de Arte, vol. 90, núm. 359, Madrid, pp. 275-286. doi: 10.3989/aearte.2017.18

El análisis de la salida delictiva de obras de arte durante la Guerra Civil padece de importantes lagunas investigadoras, ámbito que contrasta con la evacuación oficial de las obras -las enviadas a Francia a lo largo de la guerra por el Gobierno del País Vasco o por la Generalitat o las evacuadas en febrero de 1939 a Ginebra por la Junta Central del Tesoro Artístico-, que ha sido estudiada y analizada más profundamente. El motivo es evidente, mientras que en el caso de la evacuación oficial existe en lo principal una documentación de archivo importante, sin embargo,

\footnotetext{
1 acolorad@ucm.es / ORCID iD: http://orcid.org/0000-0002-6791-4048.
} 
las dificultades para el estudio de las obras salidas por vía irregular son innegables, por un lado por el carácter disperso de la documentación, además de ser ésta de una relativa fiabilidad, pero sobre todo porque esta documentación se refiere exclusivamente -dado su carácter delictivo- a aquellos casos que fueron detectados por las autoridades, tanto españolas como extranjeras. Es evidente que la localización de una nueva documentación irá enriqueciendo este estudio.

El propósito es analizar el tema tomando como base principal las fuentes directas consultadas en los archivos españoles o extranjeros y, al acudir a los escasos autores que han tratado el fenómeno de la evacuación ilícita de obras de $\operatorname{arte}^{2}$, se hará solamente en el caso de que éstos hayan acudido a su vez a otras fuentes directas. La razón es evitar por todos los medios caer en el lugar común de magnificar o exagerar este tráfico ilegal, que ha sido lo habitual en esta materia. Los testimonios y los informes franquistas que aseguran la magnitud de lo robado son numerosos, pues partían de la opinión de que existían "fabulosos depósitos [de obras de arte español robadas] que hoy se hallan diseminados por el mundo"3. Francisco Íñiguez, Comisario General del Servicio de Defensa del Patrimonio Artístico Nacional (Sdpan) en la posguerra, describía la destrucción y robo del patrimonio español durante la guerra como "obra sindical", donde incluía a "los comunistas, los anarquistas (CNT y FAI), los socialistas, en sus infinitas ramas; los trotskistas, etc., ya en bandas de pillaje, ya sueltos, acometían toda casta de empresas de robo y destrucción", añadiendo que "iban seleccionando lotes abundantísimos de todo, vendidos, una veces, y sacados de España otras, malbaratados entre chamarileros"'4.

Ateniéndose, pues, a esta realidad documental directa, en el estado actual de la investigación y a partir de nuevos datos aportados, es posible comenzar a establecer las principales características de la salida ilícita de obras de arte durante la guerra.

En primer lugar, es preciso diferenciar claramente las dos vías de salidas de obras: las que fueron evacuadas a instancias oficiales y las que fueron producto del robo o del tráfico ilegal, a pesar de que el Gobierno de Franco no hacía esta distinción, y parece que tampoco -aunque lógicamente con una intencionalidad muy distinta- varios de los escasos autores que se han acercado a este tema. Las obras evacuadas oficialmente eran de primera importancia, procedentes en su inmensa mayoría de museos e instituciones patrimoniales, mientras que las procedentes del saqueo tenían habitualmente una calidad muy inferior, originarias de iglesias o colecciones privadas; a su vez, las obras evacuadas estaban perfectamente catalogadas y serían mucho más fácilmente localizadas por los agentes franquistas en la inmediata posguerra, lo que permitió que volvieran a España; sin embargo, de las salidas por vía delictiva no se tenía control ni inventario alguno y su localización y regreso presentaron dificultades mucho mayores.

En segundo lugar, mientras que las obras evacuadas oficialmente partieron hacia el extranjero exclusivamente desde la zona republicana, y como decisión política de las instituciones - central o autonómicas- para hacerlas escapar de la guerra, los robos, saqueos y salida ilegal de obras de arte durante la guerra afectaron por igual a ambos bandos, que se vieron en muchos casos impotentes para evitarlos. Y este hecho fue el fundamento para las mutuas acusaciones lanzadas por los contendientes de que el enemigo se dedicaba a un saqueo sistemático del patrimonio, campaña especialmente lanzada por la propaganda franquista. Como puede verse por la documentación localizada, existían en las dos zonas en lucha gentes sin escrúpulos dedicadas al saqueo de obras. Este expolio se produjo de manera más intensa en el inicio de la guerra, momento en el que las autoridades, especialmente las republicanas, carecían de los medios necesarios para atajar los desmanes de ciertos elementos, aunque una vez conseguido el control y centralización de la protección del patrimonio, los robos y salidas al extranjero continuaron como una especie de goteo permanente a lo largo de toda la contienda. También es importante analizar

2 Podemos citar los escasos autores que se han acercado a esta problemática: Fernández Pardo, 2007; 2010: 201213. Martínez Ruiz, 2010. Saavedra, 2010. Otros autores han hecho referencia a este tema en sus obras de carácter más general sobre el patrimonio durante la guerra: Alted, 1984: 99-102. Álvarez Lopera, 1982: 133. Colorado, 2008: 75-80, 204-205; 2009; 2010.

3 "Sobre las colecciones del palacio de Liria": 33.

4 Íñiguez, 1941: 30. 
las medidas adoptadas por ambos gobiernos en la lucha para atajar esta sangría artística hacia el exterior, así como la respuesta que recibieron de los principales países receptores de las obras.

En tercer lugar, es preciso deslindar los diferentes sectores que pudieron estar implicados en los saqueos de obras de arte y de su exportación ilegal, aunque a veces estos profesionales de la depredación se interrelacionaban, pues los delincuentes tendían a crear auténticas redes de colaboración entre ellos. Se pueden marcar apartados específicos para cada uno de estos sectores: por un lado, los pretendidos "anticuarios" - muchas veces en connivencia con diplomáticos y responsables políticos-, aunque varios de ellos ya eran consumados exportadores de obras de arte que llevaban muchos años actuando en España; por otro, para aumentar más la complejidad, existía un segundo grupo, vinculado al de los traficantes, que se pueden calificar de estafadores, que presentaban como obras españolas piezas de origen incierto, cuando no ofrecían obras falsas como auténticas. Y finalmente, aparece el grupo de los milicianos o militantes de algunas organizaciones políticas -especialmente las anarquistas- que fueron detectados o detenidos con obras de arte o joyas. Todos ellos vieron en la guerra la ocasión idónea para sus saqueos. Una vez sentadas estas premisas de la problemática de la salida de obras al exterior, habría que ver cuál era el modus operandi de cada uno de estos sectores.

\section{Los Traficantes}

Durante la Guerra Civil existían auténticas redes de delincuentes dedicadas al robo y salida ilegal de obras de arte, dirigidas por conocidos "anticuarios" o mercaderes del arte, tanto españoles como extranjeros, que contaban en muchos casos con la colaboración de miembros de algunos partidos o sindicatos o incluso de diplomáticos y autoridades. Estos mercachifles o comerciantes sin escrúpulos fueron, sin ninguna duda, los principales responsables de las pérdidas patrimoniales, que vieron en los tiempos revueltos de la Guerra Civil una ocasión de oro para sus negocios personales.

Meses después de la entrada de las tropas franquistas en Madrid, en una carta de enero de 1940, el Ministro de Educación Nacional informaba al del Ejército sobre las indagaciones que se habían realizado por parte de los agentes del Servicio de Recuperación Artística en el Rastro y en las tiendas de anticuarios de la capital acerca de las obras robadas a los particulares y su puesta en venta, afirmando que "los objetos producto de los despojos se vendían, unos en el Rastro, alcanzando precios considerables y otros entre anticuarios, saliendo finalmente de España en número tan considerable, que según indicios, completaron el cargamento de tres barcos"5. Aunque parece una información un tanto exagerada, puede dar idea de la utilización de la vía marítima, seguramente a la que recurrieron en varios casos estos mercaderes del arte robado.

Ya en otro lugar dábamos cuenta de una serie de "anticuarios" que actuaban en la España en guerra ${ }^{6}$. A la luz de una nueva documentación podemos dar una mayor información sobre este tema. Los datos apuntan a que estos profesionales del expolio actuaban en las dos zonas en lucha, dirigiendo sus mercancías a diferentes países, siendo Francia su principal destino.

De los informes republicanos, destaca el que enviaba Ángel Ossorio, embajador de la República española en París, que data del 13 de julio de 19377. En el escrito se notificaba la información suministrada por un denunciante que apuntaba que "un cierto señor Sicard, francés, que vive en Niza y que viene frecuentemente a París y a Barcelona, de acuerdo con el Sr. Rivera Rovira, cónsul de Rumanía en Barcelona, y un hijo de este en relación con los elementos de la F.A.I., han sustraído de España cantidad de efectos de valor, oro, piedras preciosas, alhajas, cuadros, etc.". El denunciante -que esperaba a cambio de sus informaciones, además de la venganza per-

\footnotetext{
5 Carta de 19 de enero de 1940, Archivo General de la Administración (AGA), (3)5.3 51/11208.

${ }^{6}$ Colorado, 2008: 76.

7 Cuadros robados en España y depositados en Francia, carta del Subsecretario de Asuntos Exteriores al embajador de España en París de 12 de septiembre de 1939, que adjunta la carta de Ángel Ossorio, AGA, 82/04424.
} 
sonal, una recompensa- añadía que, aparte de otras obras en Cerbere, Sicard tenía una caja de caudales en la Societé Génèral de Credit Industriel et Commerciel, donde guardaba cuadros de Mantegna, de Durero, de Pierre Mignard y de Ribera ${ }^{8}$.

Era evidente que el denunciante - un tal Galle- conocía muy bien los negocios de Sicard y afirmaba que estas obras procedían "de una villa de Barcelona y por lo tanto de colección particular". El carácter de venganza personal de la denuncia y las obras apuntadas -difícilmente imaginables como procedentes de España- son datos suficientes para hacer dudar de la veracidad de los datos suministrados. Sin embargo, también sabemos que Sicard fue un traficante habitual de obras españolas durante la contienda y que fue detenido por la policía francesa en febrero de 1939 cuando intentaba pasar varias obras aprovechando la confusión del gran éxodo republicano'.

En el Archivo del Ministerio francés del Interior, existe documentación sobre una actuación policial referente a un súbdito español detenido con un alijo: en abril de 1937, el servicio de aduanas de los Pirineos Orientales detenía un coche, conducido por Valeriano Vellosa Ocariz, comerciante de Barcelona, que llevaba joyas (brillantes, perlas, broches) de un valor de 380.000 francos ${ }^{10}$.

La documentación de procedencia franquista sobre las actuaciones de estos traficantes es más tardía pero también más abundante. Según la misma, y a partir de las informaciones facilitadas por el marqués de Valdeiglesias, en 1938 se había abierto en París, en la Rue Bonaparte, "una tienda de antigüedades en la que se venden especialmente objetos religiosos procedentes de las iglesias españolas"11.

El arqueólogo Martínez Santa Olalla12 aseguraba que París era el centro de acción de "un Sr. llamado Marqués de Valverde", donde se dedicaba a la venta de obras españolas en connivencia con un anticuario de Bilbao, llamado Milicua, que las sacaba por Irún "aunque no por la aduana, sospechándose existan connivencias con funcionarios de aduana e incluso la policía" ${ }^{13}$. Después de un viaje a Alemania en junio de 1938, Martínez Santa Olalla informaba a su vez que en este país "se observa una abundancia enorme de antigüedades y cuadros de origen español que se supone que son producto de enajenaciones tanto de la zona roja como de la nuestra".

En Nueva York tenía su mercado organizado otro "anticuario", Raimundo Ruiz, de "simpatías nacionalistas, muy conocido por sus ideas católicas y con gran influencia en los centro religiosos españoles", según informaba un español dedicado al negocio de antigüedades que se personó en la representación franquista en Nueva York. Según este informante, Ruiz llevaba ya varios años dedicado a la venta de antigüedades en los Estados Unidos y viajaba con pasaporte expedido por las autoridades franquistas. En los dos últimos viajes realizados a los Estados Unidos llevaba además cartas de presentación del representante franquista en Lisboa. Obtenía las obras en la

\footnotetext{
${ }^{8}$ Según el denunciante los datos de las obras que tenía Sicard eran:

-De Andrea Mantegna la tela La alegoría de las pasiones (0'76 × 1'02), valorado en dos millones y medio de francos.

-De Alberto Durero un San Juan Bautista, fechada en 1519, (0’35 × 0’50), valorado en 3 millones y medio de francos.

-De Pierre Mignard el Retrato de una joven soñando con el amor (0'71 × 0'60), valorado en 300.000 francos.

- De Jose Ribera una Natividad (0'90 × 1'20), que estaba firmada y valorada en un millón y medio de francos.

${ }^{9}$ Carta del Director General de la Seguridad Nacional a Georges Huisman, Director General de Bellas Artes, de 8 de abril de 1939, Archives des Musées Nationaux au Louvre (AMNL), Z19.

10 Gruat/Martínez, 2011: 32.

${ }^{11}$ Carta de 12 julio de 1938 del Subsecretario de Asuntos Exteriores al Coronel Jefe del S.I.M.P, a la que se adjunta copia de la carta del marqués de Valdeiglesias, AGA, 82/4426.

12 Julio Martínez Santa Olalla (1905-1972) era un arqueólogo español, profesor de la Universidad Central, muy influido por las teorías nazis sobre los arios, que en 1939 fue nombrado Comisario General de Excavaciones por el Gobierno de Franco.

13 Nota informativa sobre ciertas actuaciones en Alemania relacionadas con el conflicto español de Relaciones Culturales del Ministerio de Asuntos Exteriores de 27 de septiembre de 1938, en la que se incluyen las informaciones de Martínez Santa Olalla, AGA, 82/4426.
} 
zona nacionalista, pero éstas procedían también de "las robadas por los rojos" que localizaba en Francia, y tenía un almacén en Nueva York "donde se hallan depositadas grandes cantidades de muebles y objetos que ha traído de España en diferentes ocasiones". Y era cierto que el tal Raimundo Ruiz era un consumado traficante de obras de procedencia española que llevaba muchos años, con su hermano Luis y previamente con su padre Pedro Ruiz, con este comercio con destino a los Estados Unidos, tal como ha estudiado María José Martínez Ruiz. Esta autora considera a los Ruiz como "los grandes protagonistas del mercado de antigüedades en Manhattan", además de "inevitables protagonistas tanto del éxito del Spanish Revival Style en Estados Unidos durante los años veinte, como del amplio proceso de despojo artístico experimentado por el patrimonio español en esos años"14.

Esta vieja práctica de los Ruiz, llevó a los franquistas a cometer ciertos errores sobre las obras expoliadas por él durante la guerra, como ocurrió en 1938 con la noticia que remitió Juan F. de Cárdenas, agente del Gobierno de Franco en Nueva York, a Jordana, ministro de Exteriores, de que Ruiz había vendido en Estados Unidos, en concreto al Metropolitan Museum, "varios tapices de la catedral de Burgos de acuerdo con algunos dignatarios de dicha catedral"15. En 1941 se demostraría que estos tapices habían sido vendidos muchos años antes de la guerra ${ }^{16}$.

Podemos deducir que muchas de las informaciones llegadas a las embajadas, cuando no se trataban de errores o falsas alarmas, eran producto de delatores que buscaban con ello la venganza personal o eliminar a un competidor -como hemos visto en los casos de Sicard en Francia o de Raimundo Ruiz en Nueva York-, lo que llevaría a relativizar los datos vertidos por éstos. La falta de inventarios de las obras saqueadas y la ausencia de expertos en patrimonio en las delegaciones diplomáticas venían a añadirse a las confusas informaciones de los delatores.

Es evidente también, por los casos vistos, que hubo connivencia de ciertos mercaderes sin escrúpulos con algunos elementos políticos, con diplomáticos, y en algunos casos -como parece ser el de Sicard en Barcelona- con cónsules honorarios, que se aprovechaban de sus privilegios para poder pasar las obras.

\section{Los estafadores}

Para aumentar más la confusión sobre el origen de las obras en el mercado internacional durante los años de la Guerra Civil, muchos traficantes quisieron hacer pasar por españolas obras de muy diversa procedencia. Este fenómeno no escapó a los responsables franquistas del patrimonio; en carta de 20 de diciembre de 1938 al Ministro de Asuntos Exteriores, Muguruza, en ese momento Comisario del Sdpan, aseguraba que "frecuentemente se intenta dar origen español a obras de arte que se encuentran en el mercado de antigüedades del extranjero con el objeto de aumentar de valor" ${ }^{\prime 7}$. A esta conclusión llegaba el autor de la carta que respondía así a una consulta que se había enviado desde Exteriores sobre "dos retratos originales de Simonis" que se encontraban en Bruselas y que se creían procedentes de algún museo público de Zaragoza. Consultado el director del Museo Provincial de Zaragoza, éste aseguró que en los últimos tiempos no había desaparecido cuadro alguno de ningún museo de la ciudad.

Suiza sería el otro gran mercado de arte europeo, y donde se produjeron varios casos de estafas con obras que se presentaban como españolas. Los informes apuntan a algunos de estos traficantes avispados, como un tal Mahler, un suizo que actuaba en Barcelona ${ }^{18}$, o un "judío

\footnotetext{
14 Martínez Ruiz, 2011: 185.

15 Carta confidencial y reservada de Juan F. de Cárdenas al conde de Jordana de 13 de julio de 1938, AGA, 82/4426.

${ }^{16}$ Carta de Juan F. de Cárdenas a Relaciones Culturales de Asuntos Exteriores de 26 de mayo de 1941, AGA, $82 / 4426$.

17 Carta de Muguruza al Ministro de Asuntos Exteriores de 20 de diciembre de 1938, AGA, 82/4426.

18 Según la información suministrada por el abogado de Zurich, Joaquín Casals Plans, en carta de 22 de julio de 1938 al representante franquista en Berna, Archivo de la Embajada de España en Berna, Suiza (AEB), Culturales.
} 
alemán" llamado Goldschmid, que realizaba sus negocios en la zona republicana ${ }^{19}$. De este último, a mediados de 1938, había en el Depósito Franco de Zúrich un depósito de su propiedad con veintidós cuadros valorados entre 1.500 .000 y 1.700 .000 francos suizos, que según afirmaba procedían de varios robos, "dos de ellos en San Sebastián y el resto en Madrid, habiendo entre los últimos dos que pertenecieron a la colección del duque de Braganza en Portugal y otros a un conde que se encuentra, parece ser, preso en la capital de España", datos que fueron transmitidos al Departamento Político Federal para impedir su venta o la salida del país $^{20}$. Goldschmid los ofrecía en venta al representante de Franco en Berna a través de un corredor de Basilea llamado Adolfo Kumli. Entre estos 22 cuadros había obras de Van Dyck, Rigaud, Luini, Sebastiano del Piombo y Tiziano. La única obra de autor español era una María con Niño de Murillo. Para garantizar la autenticidad de las obras habían sido certificadas por Clavière, experto ante el Tribunal del Sena, y por el perito suizo Ettore Rigozzi, de San Gall. Pero el marqués de Lozoya, Director General de Bellas Artes, que ya tenía mucha experiencia en detectar este tipo de negocios, comunicaría a Asuntos Exteriores que los cuadros del anticuario Goldschmid "no son auténticos ni pertenecen a ninguna colección española" 21 . Al final se trataba de una gran estafa contando como gancho la increíble historia del conde prisionero en Madrid.

A finales de 1938 llegaba a Asuntos Exteriores la noticia del representante del Gobierno de Franco en La Haya, Mario de Piniés, de que un confidente le había informado de que seis cuadros importantes - de Bellini, Rubens, Van Dyck y Leonardo- estaban a la venta en Suiza ${ }^{22}$. El asunto fue remitido a Berna por "si los cuadros a que se refiere el señor Piniés proceden de los despojos de los rojos en la zona que aún ocupan" ${ }^{23}$. La respuesta de Bárcenas, representante en Berna, fue muy esclarecedora, pues pensaba que aquellos cuadros eran "las pruebas de cómo aguzan su ingenio ciertas gentes y cómo se aprovechan de la ocasión para explotar la presunción de que vengan de España o de Rusia obras sencillamente fabricadas en cualquier parte"24.

\section{Milicianos y militantes de organizaciones políticas}

Después de ver citar a varias organizaciones políticas -especialmente a las anarquistas, pero también la documentación franquista se refiere a militantes del Partido Comunista, de la UGT o del POUM, aunque todos ellos eran englobados por los responsables franquistas bajo la denominación de "rojos" o "comunistas"- se podría desprender la idea de que ciertos comités o partidos estaban en la base de un saqueo sistemático de obras de arte en España. Pero aparte de las informaciones sesgadas de los agentes franquistas, es evidente que se trataban más de ciertos individuos que aprovechando su afiliación actuaban en provecho propio sin conocimiento en muchos casos de sus organizaciones y que se sirvieron del momento de la guerra para perpetrar sus robos. Las obras, sobre todo en el caso de los anarquistas, procedían fundamentalmente de los saqueos y asaltos a las iglesias, conventos y palacios, que Barcelona sufrió con especial intensidad.

Y seguramente detrás de estos individuos había organizaciones de traficantes extranjeros dedicados a la salida fraudulenta de las obras saqueadas. A pesar de la poca fiabilidad que ofrecen los informes del Servicio de Investigación de la Policía Militar (SIPM) -más dedicados a las alarmas propagandísticas-, en uno de junio de 1938, afirmaba que algunos "expertos" extranjeros, "casi todos de nacionalidad holandesa", se dedicaban a un negocio a gran escala consistente

19 Carta del representante franquista en Berna al ministro de Asuntos Exteriores de 22 de julio de 1938, AEB, Culturales.

${ }^{20}$ Carta del Representante de la España nacionalista en Berna al Dr. Pierre A. Feldscher, del Departamento Político Federal, de 21 de julio de 1938, AEB, Culturales.

${ }^{21}$ Carta de César Pemán al marqués de Lozoya de 23 de agosto de 1938, AEB, Culturales.

22 Carta de 6 de diciembre de 1938, AEB, Culturales.

${ }^{23}$ Carta de 17 de diciembre de 1938, AEB, Culturales.

${ }^{24}$ Carta de 8 de diciembre de 1938, AEB, Culturales. 
en adquirir las obras saqueadas a los anarquistas españoles y después venderlas en el extranjero. $\mathrm{Y}$ en concreto el informe se refería a "un judío originario de este país, un tal Van-Dam, que desde el principio de la guerra se trasladó en distintas ocasiones a Barcelona, donde adquirió de las organizaciones anarquistas muchos cuadros, joyas y objetos de arte, que después vendió con mucho provecho en los Países Bajos"25.

Pero donde parece que existía un mayor número de traficantes de arte era en Francia, especialmente en la zona de Marsella. También procedente de un informe del SIPM del mismo mes, los agentes aseguraban que "hemos podido conseguir algunos detalles relacionados con el tráfico clandestino de joyas, antigüedades y obras de arte realizado en Francia al margen del monopolio que intenta ejercer el Gobierno de Barcelona a través de sus agentes oficiales [sic.]":

Hoy podemos afirmar que lo que constituye el objeto de dicho comercio llega principalmente por vía marítima, y que el jefe principal de la organización de ventas es un anarquista boliviano, un tal Alfredo Quenta, que según parece debe gozar por completo de la confianza de los extremistas españoles, ayudados de cerca en su trabajo de un tal Moliner, que es, digamos, el experto que interviene en todas las transacciones ${ }^{26}$.

El informe se completaba con el dato de que Quenta tenía pasaporte español expedido por el Cónsul español en París y que tenía el almacén de obras en Aix-en-Provence, en concreto en el establecimiento "Antiquité David", en la rue Mirabeau, aunque podría haber otro depósito en una villa del puerto de Cassis.

Poco después, el Cónsul franquista en Marsella comunicaba "haberse enterado por buen conducto que el Jefe de la organización para la venta en Francia de los objetos de arte procedentes de España" era "el boliviano Alfredo Cuenta, de 30 años de edad nacido en La Paz" y que sus corresponsales en Marsella eran Enrique Álvarez, de 32 años natural de Valencia; Rafael Riquelma, natural de Pina de Elre (Zaragoza) y Juan Molínez Pérez, de 33 años natural de Cádiz, todos ellos con pasaportes expedidos por el Cónsul de España en Niza y en tratos comerciales con el anticuario David ${ }^{27}$. Según estas informaciones, y a pesar de que el apellido del principal responsable difiere parcialmente en los dos informes - Cuenta y Quenta-, se podría deducir que en el sur de Francia existía una red de traficantes perfectamente organizada.

En noviembre de 1938, el Subsecretario de Exteriores comunicaba al Ministro de Educación una información, llegada "por conducto digno de crédito", sobre "los hermanos italianos antifascistas Rafael y Jacome Conti, en Reims el primero y en Lille el segundo, (que) son la central de venta de objetos de arte españoles procedentes de los robos de los rojos". Esta misma fuente aseguraba que "en los Estados Unidos existe una central análoga de la Liga antifascista". Este conducto tan "digno de crédito" pasaba después a enumerar una lista de obras, que nos hace sospechar sobre la poca fiabilidad de la fuente, más dedicada a crear confusión, alarma y propaganda que a dar datos que permitieran localizar las mismas:

- Se ha presentado en este mercado una patena de la catedral de Oviedo, sin las piedras que han sido quitadas. Aquí no se vendió, ni en Holanda, pasando a Norteamérica.

- Han sido presentados aquí dos tapices del siglo XV procedentes del Escorial, valorados en dos millones de florines.

- La colección de medallas de don Jaime Bastián, de Barcelona, se encuentra ahora en los Estados Unidos.

25 Expediciones de objetos de arte, antigüedades, joyas, etc., Informe del S.I.P.M. de 27 de junio de 1938 adjunto a la carta de 9 de septiembre de 1938 de Ministro de Asuntos Exteriores al embajador de España en París, AGA, $82 / 4426$.

${ }^{26}$ El tráfico "clandestino" de joyas, antigüedades y objetos de arte, Informe del S.I.P.M. de 28 de junio de 1938 adjunto a la carta de 9 de septiembre de 1938 de Ministro de Asuntos Exteriores al embajador de España en París, AGA, $82 / 4426$. El subrayado es nuestro.

27 Anexo 3 de la carta de 25 de agosto de 1938 de Sáinz Rodriguez, Ministro de Educación, a Jordana, AGA, $82 / 4426$. 
- Parece ser que la mitad inferior de un retablo del Greco (la Resurrección de la Catedral de Toledo), se presentó en París. Uno de los dirigentes de Action Française ${ }^{28}$ intervino y hoy en día no se pudo vender. La parte superior está en una caja de caudales del banco de Inglaterra, en Londres.

- Cálices de la colección Carderera han sido vendidos en los Estados Unidos.

No se podían escribir más inexactitudes en tan poco espacio, pues que sepamos en la catedral de Toledo nunca ha habido un retablo del Greco sobre la Resurrección y en la famosa colección Carderera $^{29}$, compuesta sobre todo de dibujos y grabados (además de telas, libros raros e incunables) resulta extraño que hubiera cálices. Pero estas imprecisiones -pues sobre las obras no detalla más datos que los apuntados- no debieron ser obstáculo, pues el Ministerio de Asuntos Exteriores comunicó a sus agentes diplomáticos en Londres París y Washington la relación de obras para su búsqueda, que -sepamos- no obtuvo resultado alguno.

También en Madrid se detectó por parte franquista una red de traficantes de obras que procedían de los expoliadores. En la carta de enero de 1940 del Ministro de Educación Nacional al del Ejército, de la que ya se ha hecho mención, sobre las indagaciones que se habían realizado por parte de los agentes del Servicio de Recuperación Artística en el Rastro y en las tiendas de anticuarios, se afirmaba "la existencia de una banda de criminales que actuaba encubierta por las sindicales obreras UGT y CNT principalmente, aunque otros partidos como el Sindicalista tuvieron también intervención análoga, amparados todos por diversas personalidades" ${ }^{\prime 3}$.

\section{Las 33 cajas de Marsella}

El 28 de junio de 1937, a bordo del vapor Authorpe, salían desde Barcelona hacia Marsella 33 cajas que contenían, según la mercancía declarada, "medias de seda artificial". Expedidas por la empresa "Intercambios Comerciales, S.A.", el destinatario era el comerciante francés Charles Durban. Pero las averiguaciones posteriores demostrarían que el contenido de las cajas era muy diferente al declarado en la aduana; un agente republicano en misión especial comprobaría al acudir al depósito de la aduana de Marsella que al abrir varias de las cajas "en su interior hay lienzos y cobres pintados, vajillas y objetos de plata, cristos y otras varias cosas de ornamento para el culto católico, no pudiendo precisar exactamente el contenido de todas ellas por no haber sido posible abrirlas todas"31. El agente republicano, que consideraba "preciso llevar todas las gestiones en el más absoluto secreto", se puso en contacto con el Vicecónsul de la República en Marsella, Antonio Fernández, para comunicarle su hallazgo. El temor del agente estribaba no sólo en que se pudieran enterar las autoridades de la aduana -e interviniesen las cajas dada la falsedad de la declaración de la mercancía-, sino también que llegara a oídos de "ciertos elementos de la F.A.I. para los cuales no hay secretos en ese consulado". El objetivo del agente era evitar que se malograse con ello el rescate de las cajas de sus detentadores -miembros de la organización anarquista, según el agente- o de su posible comprador al que se las habían ofrecido. Del precio inicial de 300.000 francos habían llegado a rebajarlo a 60.000. El agente no había conseguido saber los nombres de los anarquistas al haber tenido que volver urgentemente a Barcelona.

\footnotetext{
${ }^{28}$ Action Française era una organización monárquica y violenta de ideología ultraderechista, dirigido por Charles Maurras.

${ }^{29}$ Valentín Carderera y Solano (1796-1880) fue un escritor y pintor español, además de destacado coleccionista, especialmente de dibujos y grabados.

30 Carta de 19 de enero de 1940, AGA, (3)5.3 51/11208.

${ }^{31}$ La documentación republicana aquí citada está incluida en el expediente franquista de la "Causa General de Madrid. Pieza 11: Tesoro Artístico Nacional y cultura roja", Expediente 8 titulado "Expediente sobre el envío a Francia de pinturas y objetos de arte". Centro Documental de la Memoria Histórica (CDMH), Salamanca, FC-CAUSA_GENERAL, 1557, Exp.19.
} 
Al mismo tiempo, el Consulado de Marsella informaba al Ministerio de Estado que los poseedores de las cajas, temerosos de las posibles consecuencias, habían cedido las mismas a un comerciante francés, "al parecer muy influyente entre los medios oficiales de esta población" y que decía ser amigo de la causa republicana española. El comerciante francés se presentó en el consulado afirmando que "no tenía derecho a retener una cosa que pertenecía de derecho y moralmente a la República española" y, por lo tanto ponía a su disposición las cajas, siempre que se le abonaran los gastos que había tenido que afrontar, que ascendían a 160.000 francos. El consulado, tras asegurar que este "negociante" no gozaba de "una fama muy lisonjera", recomendaba que se enviara a una persona que pudiera comprobar el valor artístico del cargamento y evaluara si valía la pena pagar la cantidad pedida ${ }^{32}$.

Este asunto también llegó a oídos franquistas, pues existe un informe de marzo de 1938 del agente francés Jaco al Estado Mayor del Cuartel General del Generalísimo, en el que daba cuenta de su misión en el sur de Francia sobre los "objetos de arte robados en España" 33 . Apuntaba este agente al servicio franquista que "hacia la mitad de 1937, cuando todavía los partidos extremistas jugaban un papel preponderante en Barcelona, se constituyó en Marsella, por estos mismos elementos y con el concurso de elementos franceses también extremistas, una sociedad comercial de garantía limitada bajo la razón de Société pour l'extension du Commerce International S.E.C.I.". Los promotores de esta sociedad eran un tal Alexandre Coupin, francés y socialista, y Julien Astolfi, de origen corso, concejal de La Ciotat y miembro del Partido Comunista, con los que trabajaban dos personas más, llamados Hernando y Urban, todos ellos vinculados al gansterismo marsellés. Según el agente francés, "el fin aparente de la Sociedad era el comercio de productos españoles en Francia, pero en realidad es para hacer pasar a Francia joyas, dinero, lingotes y todo tipo de género robado".

Pero el Gobierno de la República decidió actuar por vía judicial y diplomática para recuperar las 33 cajas de Marsella. El Fiscal General de la República recomendaba presentar una querella ante el Juzgado de Instrucción de Barcelona "por delitos de falsedad, robo y estafa" contra los responsables del cargamento. Realizado esto, había que exigir a Francia por vía diplomática la entrega de las cajas. Esta alternativa, que finalmente sería adoptada por el Ministerio de Estado, "colocaría al comerciante francés que exige 160.000 francos en una situación muy delicada ante las autoridades policiales y judiciales de Marsella y probablemente le impediría ejercitar los derechos de perjudicado, ya que tendría que declarar que conocía la falsa declaración de la mercancía y que estaba de acuerdo con los delincuentes" 34 .

Lo cierto es que las 33 cajas de Marsella fueron finalmente rescatadas y enviadas a la embajada de España en París seis meses después, en marzo de 1939. El que llevó a cabo la gestión definitiva fue Timoteo Pérez Rubio, presidente de la Junta Central del Tesoro Artístico, que viajó desde Ginebra -donde se encontraban en la SDN las obras evacuadas por la Junta en proceso de inventario- a París para hacerse cargo, entre otras, de estas obras. Por mediación de Jacques Jaujard, Director de los Museos Nacionales y de la Escuela del Louvre, consiguió que bajo amparo diplomático las cajas fueran remitidas para "amueblar dicha embajada", en un momento en el que la España de Franco ya había sido reconocida por Francia. Finalmente, acabada la guerra, las cajas pasarían a manos de los agentes franquistas del Sdpan y regresarían a España a mediados de octubre de $1940^{35}$.

Hemos podido localizar el inventario de las obras de las 33 cajas $^{36}$, aunque la información que aporta el mismo es muy escasa, pues se limita a hacer descripciones muy someras de las

32 CDMH, FC-CAUSA_GENERAL, 1557, Exp.19.

33 Informe de Jaco de $\overline{14}$ de marzo de 1938, AGA, 82/4426.

34 Informe de la Fiscalía General de la República de 25 de julio de 1938 y carta del Secretario General del Ministerio de Estado de 16 de agosto de 1938 aprobando las medidas de la Fiscalía General. CDMH, FC-CAUSA_GENERAL, 1557, Exp.19.

35 Carta de Francisco Íñiguez al marqués de Lozoya de 23 de octubre de 1940, AGA: (03)109.007 CA 1104.

${ }^{36}$ El inventario aparece incompleto en el expediente de la Causa General antes citado, pero se conserva íntegro tanto en el AMNL (Z19) como en el Archivo del Museo Extremeño e Iberoamericano de Arte Contemporáneo (Fondo Timoteo Pérez Rubio). 
piezas que contenía el cargamento (la mayoría piezas como porcelanas, platos, candelabros, estatuillas, etc.). Lo que sí destaca es que las diez primeras cajas del inventario almacenaban unas 200 pinturas, de las que no se aportan los títulos ni las medidas, sólo los soportes (tabla, lienzo, cartón, cobre...), y únicamente se identifican a los autores de dos obras: una que se atribuye a "H. de Hollendal" y la otra a "A. Sánchez Palma".

\section{La política de ambos gobiernos}

Es indudable que los dos gobiernos en lucha conocían sobradamente las redes de traficantes y los robos y exportaciones ilegales y así lo atestigua la documentación de archivo. Ambos utilizarían estos datos del campo enemigo para lanzar campañas para acusar al contrario de poner en venta el patrimonio español, aunque en esta empresa la propaganda franquista fue mucho más eficaz que la republicana.

El tráfico de obras de arte, especialmente de origen eclesiástico, que había sufrido España desde finales del siglo XIX, con la intensificación durante los años veinte del siglo XX, había provocado que el país se armara con una serie de medidas legislativas que tenían como principal objetivo combatir este expolio con destino al extranjero. El Real Decreto de 9 de enero de 1923 obligaba a la Iglesia a obtener una autorización previa del Ministerio de Gracia y Justicia para cualquier enajenación de obras de $\operatorname{arte}^{37}$. Pero sería durante los mandatos de Ricardo de Orueta como Director General de Bellas Artes cuando la República española desplegó una eficaz normativa y de largo alcance. Tal como ha estudiado Miguel Cabañas ${ }^{38}$, las propuestas de Orueta se materializaron, ya en la etapa constituyente, en el Decreto de 22 de mayo de 1931 -que estableció la autorización previa del Ministerio de Instrucción Pública y de Bellas Artes para cualquier enajenación de bienes muebles y de la Dirección General de Bellas Artes en el de los inmuebles-, y en la Ley de 10 de diciembre de 1931, que regulaba la enajenación de los bienes artísticos, históricos o arqueológicos con una antigüedad superior a los cien años con el derecho de tanteo por parte del Estado. Todo este proceso legislativo promovido por Orueta culminaría con el "novedoso y avanzado" -en palabras de Cabañas ${ }^{39}$ - artículo 45 de la nueva Constitución de 1931, que rezaba que "toda la riqueza artística e histórica del país, sea quien fuere su dueño, constituye el tesoro cultural de la Nación, y estará bajo la salvaguardia del Estado, que podrá prohibir su exportación y enajenación y decretar las expropiaciones legales que estimare oportunas para su defensa", que se materializaría, ya durante el bienio reformador, en la Ley de Protección del Tesoro Artístico Nacional de 13 de mayo de 1933.

Pero a pesar de la existencia de esta normativa interna, también es cierto que ambos gobiernos intentaron infructuosamente que los países receptores de obras tomaran medidas para evitarlo. A pesar de las repetidas reclamaciones que los dos gobiernos presentaron ante las autoridades extranjeras, los resultados fueron prácticamente nulos. Las respuestas de los gobiernos de Francia e Inglaterra -países privilegiados en la llegada de obras de origen español-, son un ejemplo de que ninguno de ellos quiso ofrecer garantía alguna para paralizar la sangría de obras.

En el bando franquista se encontraban además con una dificultad añadida: cualquier gestión de lucha contra el tráfico de obras en Francia se veía entorpecida por la "actitud inhibitoria" de su agente en París, Quiñones de León, que en opinión del ministro de Educación Nacional, en carta remitida al ministro de Asuntos Exteriores, "no sólo no ayuda sino que es un verdadero obstáculo para cualquier actuación (...) y que utiliza su posición en París para cuestiones personales". El ministro se lamentaba de que mientras Quiñones "tenga el monopolio de la actuación en París y pueda poner vetos a otras actuaciones y dificultarlas no se podrá hacer nada". Concluía que, mientras tanto "se está organizando un mercado metódico de nuestro patrimonio artístico

\footnotetext{
37 Martínez Ruiz, 2011: 158.

38 Cabañas, 2009a; 2009b. Bolaños/Cabañas, 2014.

${ }^{39}$ Cabañas, 2009a: 176.
} 
contemplándolo nosotros de brazos cruzados"40. El ministro de Educación también añadía como anexo a su carta un informe de Muguruza en la que recordaba que las instrucciones de la Dirección General de Seguridad Nacional del Ministerio francés de Interior de 4 de julio de 1938 cursada a las autoridades de la policía criminal, el Gobierno francés se limitaba invitar a dichas "autoridades a proponer la expulsión de los ciudadanos extranjeros que se dediquen a semejante tráfico"41.

En respuesta a las quejas del Ministro de Educación Nacional, el 6 de septiembre de 1938, Teixidor, Jefe de Relaciones Culturales de Asuntos Exteriores, elaboró un informe sobre la "Expoliación del Tesoro Artístico y comercio a que ha dado lugar en Francia"42, que más parecía una justificación de las actuaciones desarrolladas por el organismo que presidía y una defensa de Quiñones de León ante las acusaciones lanzadas por el Ministro de Educación. Una vez más -pues será una constante a lo largo de la guerra y de la posguerra- las tensiones entre Educación y Exteriores se manifestaban en la cuestión del rescate de obras de arte en el extranjero.

Pero en el informe de Teixidor se aclaraba que, según la circular de la Dirección General de Seguridad Nacional francesa a la que hacía referencia Muguruza, no se sancionaba "el tránsito pues se permite la admisión de objetos preciosos con la expresa condición de que no den lugar a ninguna operación que afecte a su propiedad durante su permanencia en Francia". En pocas palabras, que Francia aceptaba la entrada de estas obras en su territorio pero prohibía la venta de las mismas -previéndose como sanción la expulsión de Francia para los contrabandistas extranjeros-, pero lo cierto es que al permitir el tránsito se dejaba la puerta abierta a la entrada de obras producto del robo y el contrabando. Y al mismo tiempo no se tomaban medidas eficaces contra los traficantes franceses de obras españolas.

La postura inglesa no distaba mucho de la francesa. Ante un requerimiento del Gobierno de Franco ante la embajada británica sobre la entrada en dicho país de obras de procedencia española, ésta respondería en abril de 1937:

El Gobierno de S.M. nunca sería parte consciente, desde luego, en la adquisición de objetos de arte robados en España pero, sin embargo, no tiene poder alguno, según la legislación vigente, para impedir la llegada y venta de esta clase de propiedad en el Reino Unido y no sería práctico, por otra parte, introducir por el momento modificaciones en la misma ${ }^{43}$.

El mercado ilegal de antigüedades hacia el extranjero había preocupado al Gobierno de la República desde el mismo inicio de la guerra. Ya en agosto de 1936 había enviado una circular a todos los diplomáticos de embajadas y consulados previniendo sobre esta contingencia ${ }^{44}$. Viendo además la inutilidad de las gestiones ante los gobiernos extranjeros, el 26 de marzo de 1938 llegó a declarar ilegal y a prohibir todo comercio de antigüedades y obras de arte ${ }^{45}$, incluyendo "en esta prohibición todos los objetos de las artes mayores y de las artes industriales cualquiera que sea la materia en la que estén ejecutados y el procedimiento de ejecución, incluidos muebles y monedas". Solamente exceptuaba de esta prohibición las obras de los artistas vivos, con residencia en la zona leal, y los productos de las artes populares fabricadas en serie. A su vez, incluía en la prohibición la venta de los libros antiguos anteriores a 1837 y de cualquier tipo de documento.

Como vemos, los dos gobiernos españoles se sentían impotentes ante el tráfico clandestino de obras hacia el extranjero, pues a pesar de las constantes reclamaciones ante los gobiernos europeos éstos no cambiaron su legislación y, en el caso de la República, tuvo que llegar -aunque

\footnotetext{
40 Carta de Sáinz Rodríguez a Jordana de 25 de agosto de 1938, AGA, 82/4426.

${ }^{41}$ Carta de Muguruza de 20 de agosto de 1938, que se adjunta como anexo 2 a la carta de 25 de agosto de 1938 de Sáinz Rodríguez a Jordana, AGA, 82/4426.

${ }^{42}$ Expoliación del Tesoro Artístico y comercio a que ha dado lugar en Francia, informe de Teixidor de 6 de septiembre de 1938, AGA, 82/4426.

43 Nota de la Embajada británica al Secretario General del Estado de 16 de abril de 1937, AGA, 82/4426.

${ }^{44}$ Circular $N .^{\circ} 1725$, AGA, 82/3240.

45 Decreto de 26 de marzo de 1939, Gaceta de la República de 28 de marzo de 1939.
} 
evidentemente ya era demasiado tarde- a prohibir toda venta de antigüedades. De todas maneras, y a pesar de relativizar la magnitud que el franquismo atribuyó a esta salida de obras producto del robo, es indudable que existió un mercado de obras de arte de procedencia española $-o$ de pretendido origen español- que se extendía a varios países ${ }^{46}$. El principal destino era Francia y especialmente París, centro mundial del mercado de obras de arte. Además esta exportación ilegal se extendía hacía América y a otros países europeos - especialmente Suiza, Inglaterra, Holanda, Bélgica o Alemania. Esperamos que con estos nuevos datos hayamos contribuido al estudio de tema tan complejo, y que sirva de acicate para nuevas aportaciones.

\section{BIBLIOGRAFÍA}

Alted Vigil, Alicia (1984): Política del Nuevo Estado sobre el Patrimonio Cultural y la Educación durante la guerra civil española. Madrid: Ministerio de Cultura.

Álvarez Lopera, José (1982): La política de bienes culturales del gobierno republicano durante la Guerra Civil española. Madrid: Ministerio de Cultura.

Bolaños Atienza, María/Cabañas Bravo, Miguel (coords.) (2014). En el frente del arte: Ricardo de Orueta 1868-1939, catálogo de exposición, Madrid: Acción Cultural Española.

Cabañas Bravo, Miguel (2009a). "La Dirección General de Bellas Artes republicana y su reiterada gestión por Ricardo de Orueta (1931-1936)”. En: Archivo Español de Arte, Abril-junio, 326, Madrid, pp. 169-193.

Cabañas Bravo, Miguel (2009b). "Ricardo de Orueta y la Dirección General de Bellas Artes durante la II República y la guerra civil”. En: Cabañas, M.; López-Yarto, A. y Rincón, W. (coords.): Arte en tiempos de guerra. Madrid: CSIC.

Colorado Castellary, Arturo (2008): Éxodo y exilio del arte. La odisea del Museo del Prado durante la Guerra Civil. Madrid: Cátedra.

Colorado Castellary, Arturo (2009). "La diáspora del patrimonio artístico español”. En: Letra Internacional, N. 102 , Madrid, pp. 24-35.

Colorado Castellary, Arturo (2010). "La política franquista sobre el patrimonio en la primera posguerra”. En: Colorado Castellary, Arturo (ed.): Patrimonio, Guerra Civil y Posguerra. Madrid: Universidad Complutense de Madrid, pp. 99-122.

Fernández Pardo, Francisco (2007): Dispersión y destrucción del patrimonio artístico español. Vol. V: Desde la Guerra Civil a nuestros dias (1936- 2007). Madrid: Fundación Universitaria Española.

Fernández Pardo, Francisco (2010): "De cómo afectó la Guerra Civil a nuestra platería y joyería”. En: Colorado Castellary, Arturo (ed.): Patrimonio, Guerra Civil y posguerra. Madrid: Universidad Complutense de Madrid, pp. 201213.

Gruat, Cédric/Martínez, Lucia (2011): L'échange. Les dessous d'une négociation artistique entre la France et l'Espagne. 1940-1941. París: Armand Colin.

Íñiguez, Francisco (1941): “El arte en España durante la guerra. Su destrucción, dispersión y rescate”. En: Revista Nacional de Educación, N. ${ }^{\text {o }}$ 5, Madrid, pp. 29-40.

Martínez Ruiz, María José (2010): "No se perdió más en la guerra... La merma del patrimonio castellano leonés, más debido al abandono y al negocio de antigüedades". En: Colorado Castellary, Arturo (ed.): Patrimonio, Guerra Civil y posguerra. Madrid: Universidad Complutense de Madrid, pp. 215-228.

Martínez Ruiz, María José (2011): "Entre negocios y trapicheos. Anticuarios, marchantes y autoridades eclesiásticas en las primeras décadas del siglo XX: el caso singular de Raimundo Ruiz". En: Pérez Mulet, Fernando y Socias Batet, Inmaculada (eds.): La dispersión de objetos de arte fuera de España en los siglos XIX y XX. Barcelona: Publicacions i Edicions, Universitat de Barcelona; Cádiz: Universidad de Cádiz, Servicio de Publicaciones, pp. 151-190.

Saavedra Arias, Rebeca (2010): "El mercado negro de obras de arte durante la guerra civil española (1936-1939). Una propuesta de análisis para su estudio". En: Colorado Castellary, Arturo: Patrimonio, Guerra Civil y posguerra. Madrid: Universidad Complutense de Madrid, pp. 189-199.

"Sobre las colecciones del palacio de Liria" (1941). En: Arte Español. Segundo trimestre, Madrid, pp. 32-33.

Fecha de recepción: 18-I-2016

Fecha de aceptación: 19-V-2016

46 Un capítulo aparte sería el de los coleccionistas privados que aprovecharon el momento de la guerra, dado el colapso del Estado, y la permisividad franquista de la posguerra para sacar sus obras al extranjero para venderlas. 